\title{
Os museus portugueses e a Web 2.0
}

\author{
Alexandra Raquel Pedro \\ Colaboradora do Museu de Alberto Sampaio (Portugal). \\ Mestre em ciência da informação (Universidade do Minho/ \\ Portugal). Doutoranda em museologia (Faculdade de Letras \\ da Universidade do Porto/ Portugal). \\ E-mail: alexandrapedropeixes@gmail.com
}

\section{Resumo}

O presente artigo dá a conhecer um projecto de investigação que teve como objectivo determinar e analisar a partir da observação dos sítios Web dos museus portugueses quais as ferramentas Web 2.0 usadas por estas instituições no desenvolvimento das suas actividades. Neste sentido, foram seleccionados como amostra os 125 museus pertencentes à Rede Portuguesa de Museus. Os resultados obtidos permitem-nos afirmar que utilização das ferramentas Web 2.0 por parte dos museus portugueses analisados está numa fase inicial. A ferramenta mais usada é o blogue. Foram, também, identificados projectos pioneiros ao nível dos wikis, Licenças Creative Commons, Youtube, Flickr e redes sociais on-line.

\section{Palavras-chave}

Ferramentas Web 2.0. Museu. Sítio Web.

\section{Portuguese museums and Web 2.0}

\begin{abstract}
This article presents the results of an investigation work that had as main objective the determination and analysis of the Web 2.0 tools used by Portuguese museums in the development of their activities. The selected samples were the 125 museums from the Rede Portuguesa de Museus. The conclusion is that this practice is only at an early stage. The most used tool is the blog. Pioneer projects were also identified namely wikis, Creative Commons Licenses, Youtube, Flickr and online social networks.
\end{abstract}

\section{Keywords}

Web 2.0 tools. Museum. Web site.

\section{INTRODUÇÃO}

No final do século XX o mundo ocidental viu emergir as novas tecnologias de informação e comunicação (TICs), que deram origem a uma revolução digital/ informacional que potenciou o nascimento da sociedade da informação. As TICs estão hoje presentes em múltiplos aspectos do quotidiano humano e vieram modificar profundamente o funcionamento do mundo (MSI, 1997). De facto, nesta "aldeia global" em que vivemos, onde informação é poder, as TICs vieram criar uma plataforma para a livre circulação de informação, ideias e logicamente conhecimento.

Neste âmbito, a Internet assume relevo ao esbater as tradicionais fronteiras do espaço e do tempo, levando a que a comunicação e os acontecimentos sucedam em tempo real e dando origem a uma "realidade virtual". Os cidadãos, sobretudo os ocidentais, recorrem cada vez mais à Internet enquanto ferramenta de comunicação, fonte de informação e mesmo instrumento de apoio ao desenvolvimento das mais diversas actividades, inclusivamente as profissionais (MSI, 1997).

Assim, é importante que as instituições marquem presença neste mundo digital em rede, já que a Internet pode mesmo ser a primeira fonte de informação consultada. Embora a Internet só tenha começado a dar os primeiros passos na década de 60 do século passado (Cardoso, 2003), o seu desenvolvimento foi extremamente rápido. Actualmente, fala-se já numa Web 2.0.

O conceito e tudo que este envolve nasceu em consequência da crise que afectou o mercado da Internet e que originou a falência de várias empresas durante o outono de 2001. Contudo, apesar desta crise, nos anos que se seguiram a importância da Internet e a sua difusão continuaram a aumentar. 
Foi então que numa sessão de brainstorming entre a O'Reilly Media e a MediaLive International, onde se discutia a possibilidade da realização futura de uma conferência sobre a Internet, os intervenientes, partindo da expansão vivida pela Internet mesmo após a crise de 2001 e apontando que as empresas que tinham sobrevivido à crise pareciam ter características em comum, usaram pela primeira vez o termo Web 2.0 para aludir a uma evolução da Internet. Nasceu, assim, em 2004, a Web 2.0 Conference, que tem vindo a realizar-se desde então, embora tenha sido rebaptizada de Web 2.0 Summit. Foi a partir da realização destas conferências, totalmente dedicadas à discussão desta temática, que o conceito se popularizou e começou a ser fortemente debatido (O’REILLY, 2005).

De acordo com Tim O’Reilly (2006), falar da Web 2.0 é falar da "revolução dos negócios na indústria dos computadores causada pela mudança para uma Internet como plataforma e uma tentativa de entender as regras para alcançar o sucesso nesta nova plataforma. A mais importante destas regras é a seguinte: desenvolver aplicações que aproveitem os efeitos do trabalho em rede para se tornarem melhores à medida que são utilizadas por mais pessoas", ou seja, aproveitando o que se chama de inteligência colectiva.

Trata-se de um conceito polémico que, para alguns, como Tim O'Reilly, reporta-se a uma segunda geração de Internet (O’Reilly, 2005), enquanto para outros, como o próprio pai da World Wide Web Tim Berners-Lee (2006), não se justifica, pois refere-se à evolução tecnológica natural da Web. Acima de tudo o que está em causa é a existência de uma Internet que se distingue por disponibilizar ferramentas (na sua maioria gratuitas e de fácil utilização) que possibilitam maior participação do utilizador, sendolhe permitido gerar, organizar e publicar informação ou então enriquecer a informação desenvolvida por outros, avaliando-a ou fazendo comentários (BOTTENTUIT JUNIOR; COUTINHO, 2008). Neste universo, os conceitos de colaboração e comunidade ganham destaque. Projectos como a Wikipedia e os populares blogues fazem parte integrante da Web 2.0.
Os museus e a actividade museológica não são imunes aos benefícios mas também às exigências introduzidas pelas TICs. Isto porque se, por um lado, estas vieram facilitar o trabalho a desenvolver, permitindo fazer mais e melhor, atingindo um público alargado, por outro, aumentaram os padrões de exigência dos utentes destas instituições culturais. Os amantes dos museus, quer como meros visitantes, quer como investigadores, exigem que estas instituições forneçam mais informação sobre as suas actividades e colecções, demandando ao mesmo tempo que esta informação seja mais completa e nos casos pertinentes cientificamente válida (MARTY, 2007; ZORICH, 2007).

Em termos tecnológicos, a Internet assume papel preponderante, pois veio oferecer aos museus a possibilidade de ligar documentos de texto, imagem, som e vídeo de modo interactivo, permitindo-lhes apresentar as suas colecções e informações com elas relacionadas a todo o mundo, a partir de um acesso remoto (SCHWEIBENZ, 2004).

Nesta lógica, nos últimos anos, os museus têm marcado presença na Internet, nomeadamente através do desenvolvido de sítios Web próprios. Estes traduzem a ideia da construção de uma extensão digital do museu na Internet, aproximando estas instituições dos seus visitantes. De facto, através de sítios Web, os museus têm a possibilidade de difundir informação e disponibilizar um conjunto de serviços que podem, tanto induzir uma visita ao museu real (THOMAS; CAREY, 2005) e, quanto, satisfazer as necessidades de pessoas que por razões várias não podem deslocar-se às suas instalações físicas (MARTY, 2007A).

Igualmente acompanhando a evolução da própria Internet, vários museus têm vindo a utilizar as ferramentas da Web 2.0 na concretização das suas actividades, desenvolvendo iniciativas que procuram aproximar museus e comunidade. Referimonos à criação de blogues, à integração em redes sociais on-line como o MySpace, às ferramentas de partilha de recursos como o Youtube, entre muitos outros. A este nível, é de destacar o norte- 
americano Brooklyn Museum que oferece no seu sítio Web uma secção inteiramente dedicada à sua comunidade on-line, onde referencia todas as ferramentas Web 2.0 que utiliza para difundir as suas actividades e colecções e dialogar com os apreciadores do museu.

Em Portugal têm sido produzidos poucos trabalhos sobre a utilização que os museus têm vindo a fazer destas ferramentas. Neste contexto, decidimos desenvolver um estudo geral sobre esta temática estabelecendo como objectivo: determinar e analisar a partir da observação dos sítios Web dos museus portugueses quais as ferramentas Web 2.0 usadas por estas instituições no desenvolvimento das suas actividades, nomeadamente na sua relação com os públicos.

\section{FERRAMENTAS WEB 2.0}

Com vista ao cumprimento do nosso objectivo, levamos a cabo uma revisão de literatura que permitiu aferir quais as ferramentas Web 2.0 já utilizadas por museus em nível internacional. São elas:

- Blogues - "página Web que se pressupõe ser actualizada com grande frequência através da colocação de mensagens constituídas por imagens e/ou textos normalmente de pequenas dimensões e apresentadas de forma cronológica, sendo as mensagens mais recentes normalmente apresentadas em primeiro lugar” (GOMES, 2005).

- Ferramentas de criação de redes sociais on-line permitem a comunicação e a partilha de recursos entre amigos e familiares. $\mathrm{Na}$ Internet existem vários sítios de redes sociais tais como o MySpace, o Facebook, o Hi5 e a um nível mais desenvolvido e a três dimensões o Second Life.

- Ferramentas de partilha de recursos - são várias as ferramentas on-line que permitem a partilha de recursos. É o caso do Youtube, para partilha de vídeos, e do Flickr, para partilha de fotografias/ imagens.
- Wikis - trata-se de "uma página ou conjunto de páginas Web que podem ser facilmente editadas por qualquer pessoa que a elas tenha acesso" (ANDERSON, 2007), ou seja, é "um sítio na Web para o trabalho colectivo de um grupo de autores" (BOTTENTUIT JUNIOR; COUTINHO, 2008).

- Bookmarking e colecções digitais pessoais - no âmbito dos museus o conceito bookmarking é o nome dado a um conjunto de tecnologias que permitem ao utilizador guardar informação de interesse pessoal para futura utilização. No que respeita aos sítios Web dos museus, bookmarking significa dar ao utilizador a possibilidade de seleccionar e guardar informações fornecidas on-line sobre as suas obras de arte ou artistas favoritos. As obras seleccionadas são depois integradas numa página pessoal, podendo ser posteriormente visitadas, enviadas a amigos e família ou, em alguns casos, partilhadas com outros visitantes como se fossem exposições virtuais. Os utilizadores criam, assim, as suas próprias colecções digitais (FILIPPINI FANTONI; BOWEN, 2007).

- Social tagging - prática de atribuir tags ou palavraschave pessoais a recursos digitais (ex: vídeos, sítios Web, etc.) (ANDERSON, 2007). No contexto museológico aplica-se muito particularmente às bases de dados das colecções.

- Podcasts - são ficheiros áudio ou vídeo (neste caso também chamados vidcasts ou vodcasts) gravados em qualquer formato digital (ex: MP3) e distribuídos on-line num formato RSS. Basicamente, os ficheiros ficam armazenados num servidor hospedeiro na Internet e os utilizadores subscrevem RSS feeds, recebendo, desta forma, informação sobre novos podcasts, à medida que estes são disponibilizados (WIKIPEDIA, 2008).

- RSS feeds - são listas actualizadas de conteúdos Web (WIKIPEDIA, 2008A). Resumidamente, a informação de um sítio Web é integrada num feed (que usa o formato RSS) que é enviado aos utilizadores que o subscrevem (ANDERSON, 2007).

Ci. Inf., Brasília, DF, v. 39 n. 2, p.92-100, maio/ago., 2010 
- Licenças Creative Commons - licenças gratuitas que permitem a um autor publicar conteúdos na Web especificando as condições de utilização desses conteúdos. (CREATIVE, 2008).

\section{METODOLOGIA}

As ferramentas Web 2.0 identificadas na revisão de literatura realizada foram inseridas numa pequena grelha usada como instrumento de análise dos sítios Web dos museus portugueses.

Diante da impossibilidade de estender a nossa análise a todo o tecido museológico português, foram seleccionados como amostra os 125 museus que integram a Rede Portuguesa de Museus (RPM). A escolha desta amostra resulta do facto de os museus pertencentes à RPM terem sido objecto de um processo de credenciação, originando o reconhecimento oficial da sua qualidade técnica enquanto museus.

Seguiu-se a identificação dos sítios Web desses museus, que foi feita a partir da consulta da página da RPM (http://www.imc-ip.pt/pt-PT/ $\mathrm{rpm} /$ museus_rpm/HighlightList.aspx) onde são fornecidas informações-base sobre cada instituição museológica. Contudo, nessa recolha detectamos que nem todos os museus possuíam sítio Web próprio. Para além disto, vários museus do Instituto dos Museus e da Conservação apresentavam as suas páginas em reestruturação ao abrigo da Resolução do Conselho de Ministros no $155 / 2007$, de 2 de outubro, que determinou a obrigatoriedade de os sítios da Internet dos serviços e organismos públicos portugueses respeitarem os padrões internacionais em matéria de acessibilidade aos respectivos conteúdos. Assim, de forma a alargarmos a nossa amostra, para além dos museus com sítio Web próprio, foram ainda considerados os sítios Web das instituições que tutelam os museus, sempre que referidos na página da RPM e apenas nos casos em que o espaço dedicado a cada museu compreende um menu com pelo menos 4 hiperligações para além da página de entrada. No final, tivemos em conta 72 sítios Web. Esses sítios foram identificados entre agosto e setembro de 2008. Por sua vez, a grelha de análise foi aplicada aos 72 sítios Web entre setembro e novembro de 2008 .

Adicionalmente e nos casos aplicáveis, realizou-se uma busca no sítio Web de cada ferramenta Web 2.0 na tentativa de detectar qualquer um dos museus da RPM. Assim, para os blogues foi feita uma pesquisa a partir do Google Blog Search e do Technorati. Para as redes sociais on-line e ferramentas de partilha de recursos, a busca fez-se no sítio Web dos respectivos serviços.

\section{APRESENTAÇÃO DE RESULTADOS}

\section{Blogues}

No decorrer do nosso estudo à blogosfera e à presença dos museus portugueses nesta dimensão da Internet deparamo-nos com diferentes realidades. Assim, pudemos observar que:

- sete museus possuem sítios Web e blogues em simultâneo, sendo que destes sete museus, um possui não apenas um mas dois blogues e outro três, o que perfaz um total de dez blogues identificados;

- dois museus têm os seus sítios Web em reestruturação e, portanto, inacessíveis, reencaminhando os visitantes para blogues;

- quatro museus pertencentes à RPM que não possuem sítios Web mantêm, todavia, blogues (estes foram identificados durante a nossa pesquisa nos motores de busca de blogues). Também neste caso um dos museus apresenta dois blogues publicados em simultâneo, originando um total de cinco blogues.

Concluindo, foram detectados 17 blogues pertencentes a um total de 13 museus.

\section{Ferramentas de criação de redes sociais on-line}

Relativamente às ferramentas de criação de redes sociais on-line, os resultados obtidos a partir da análise dos sítios Web dos museus foram nulos. 
Contudo, adicionalmente, foi efectuada uma busca aos sítios Web do MySpace, Facebook, Hi5 e Second Life. Quanto ao Facebook e ao Second Life, os resultados permaneceram nulos. Todavia, nos sítios Web do MySpace e do Hi5 o feedback foi ligeiramente diferente.

No sítio do MySpace a nossa pesquisa levou-nos até à Fundação de Serralves. Contudo, esta conta apenas com quatro amigos e a falta de conteúdos demonstra inactividade, não sendo claro se a iniciativa partiu da própria fundação, muito embora o símbolo da instituição esteja presente.

Já no Hi5, encontramos o Museu Municipal Amadeo Souza Cardoso a cujo perfil, infelizmente, não conseguimos ter acesso, pelo que não nos foi possível aferir se se trata efectivamente de uma iniciativa institucional e qual a sua popularidade.

Foram, igualmente, detectados grupos formados em torno de sete museus da RPM, criados por particulares que se declaram apreciadores destas instituições. $\mathrm{O}$ facto de existirem grupos formados em torno destes museus é um claro sinal de que há interesse por parte dos membros desta rede social em conhecer melhor estas instituições culturais e em discutir as questões que a estas dizem respeito.

\section{Ferramentas de partilha de recursos}

No decurso da análise que foi efectuada aos sítios Web dos museus da RPM, não foi detectado qualquer museu que tenha integrado a comunidade Flickr.

Contudo, a pesquisa feita no sítio Web do serviço permitiu-nos detectar a presença da Fundação Portuguesa das Comunicações, entidade que tutela o Museu das Comunicações e que apresenta, entre outras, imagens dos objectos expostos nas salas do museu.

No que respeita ao recurso ao Youtube pudemos identificar três museus que disponibilizam vídeos usando esta ferramenta: o Museu das Comunicações; o Museu da Fundação Calouste Gulbenkian e o Museu de Arte Contemporânea de Serralves.

\section{Wikis}

No contexto do nosso estudo apenas identificamos um wiki da responsabilidade de um museu, a CasaMuseu Camilo Castelo Branco. Trata-se do "Wiki Camilo" relacionado, como o próprio nome indica, com a figura do escritor Camilo Castelo Branco.

Este wiki assume-se como um projecto comunitário que tem como objectivo "promover e dar a conhecer o património literário de Camilo Castelo Branco: personagens e lugares por onde passou, viveu e fez viver as suas personagens, num cruzamento entre a sua vida e a sua obra, baseado na participação activa dos utilizadores, capitalizando as experiências e opiniões pessoais dos leitores de Camilo, dos conhecedores desta temática, assim como as do meio académico e dos investigadores desta área, tornandose num repositório para o conhecimento colectivo sobre a obra do escritor" (ALVIM, 2008).

\section{Licenças Creative Commons}

A este nível foi detectada a utilização por parte da Casa-Museu Abel Salazar de Licenças Creative Commons aplicadas às fichas de inventário da base de dados das colecções disponibilizada on-line. Associada a cada ficha de inventário encontra-se o símbolo destas licenças. Clicando nesse símbolo é possível aceder a uma página onde constam as condições de utilização dos conteúdos, nomeadamente as fotografias.

Deste modo, de forma simples e inequívoca, o utilizador toma conhecimento das condições em que poderá usar as fotografias disponibilizadas, ao mesmo tempo que a Casa-Museu Abel Salazar tem a garantia de ter os seus recursos licenciados e, assim, protegidos e salvaguardados.

\section{Bookmarking e colecções digitais pessoais, Social tagging, Podcasts e RSS feeds}

Durante a nossa análise não detectamos qualquer museu que possibilite aos seus utilizadores a prática do bookmarking com a consequente criação de colecções digitais pessoais, a atribuição de tags aos recursos digitais, a disponibilização de podcasts ou a subscrição de RSS feeds.

Ci. Inf., Brasília, DF, v. 39 n. 2, p.92-100, maio/ago., 2010 


\begin{tabular}{l|c|c}
\hline Ferramenta Web 2.0 & Número de museus & Valores percentuais \\
\hline Blogues & 13 & $10,4 \%$ \\
\hline Redes sociais on-line & 2 & $1,6 \%$ \\
\hline Flickr & 1 & $0,8 \%$ \\
\hline Youtube & 3 & $2,4 \%$ \\
\hline Wikis & 1 & $0,8 \%$ \\
\hline Licenças Creative Commons & 1 & $0,8 \%$ \\
\hline $\begin{array}{l}\text { Bookmarking e colecções } \\
\text { digitais pessoais }\end{array}$ & 0 & $0 \%$ \\
\hline Social tagging & 0 & $0 \%$ \\
\hline Podcasts & 0 & $0 \%$ \\
\hline RSS feeds & 0 & $0 \%$ \\
\hline
\end{tabular}

\section{DISCUSSÃO DE RESULTADOS}

Os resultados obtidos no âmbito deste estudo mostram claramente que a utilização das ferramentas Web 2.0 pelos museus portugueses se encontra, ainda, em fase inicial, começando agora a dar os primeiros passos.

A este nível, a realidade portuguesa parece acompanhar a tendência vivida em França. O panorama francês é retratado por Gaëlle Crenn e Geneviève Vidal, num artigo de 2007. Neste, os autores, analisando os sítios Web de 10 museus franceses, concluem que, à parte de alguns casos concretos, a utilização das tecnologias Web 2.0 permanece relativamente rara entre os museus. Afirmam que os profissionais da museologia referem a intenção de desenvolver iniciativas mas a sua execução demora (CRENN; VIDAL, 2007).

Contudo, noutros países, nomeadamente anglosaxónicos, alguns museus têm-se afirmado pela experimentação a este nível e a progressiva adopção de um número crescente destas ferramentas mostra que tem valido a pena. É o caso do Brooklyn Museum e do Museum of London, entre outros.

Obviamente, o impacto real de muitas destas iniciativas está, ainda, por ser avaliado e apenas o futuro mostrará até que ponto constituíram uma boa aposta, mas ser pioneiro implica quase sempre uma grande dose de risco.

Ci. Inf., Brasília, DF, v. 39 n. 2, p.92-100, maio/ago., 2010
Contudo, acreditamos firmemente que estas ferramentas podem ajudar os museus no cumprimento de muitas das suas funções, sobretudo no que respeita à conquista e fidelização de públicos.

De todas as ferramentas Web 2.0 detectadas, a que apresenta maior adesão são os blogues, já que foram detectados 17 blogues pertencentes a 13 museus. Olhando para o universo total dos 125 museus considerados para análise, estes resultados podem parecer pouco significativos. Todavia, se consideramos que o primeiro blogue ligado à museologia em Portugal, o e MUSEU (Carvalho, 2008), surgiu em 2003, e que dos 17 blogues identificados, 12 surgiram em 2008, estes resultados podem ser vistos como um indicador de um aumento da atenção que os museus portugueses têm vindo a dar a esta ferramenta. Prova da crescente importância desta temática no contexto português foi a realização do $1^{\circ}$ Encontro de Blogues de Museus que teve lugar no Museu da Chapelaria, a $1^{\circ}$ de março de 2008.

Resultados bem menos significativos foram os obtidos em relação às ferramentas de partilha de recursos, como o Youtube e o Flickr. Realce-se que estes serviços podem ser usados com vários propósitos no ambiente museológico: promoção de exposições ou outros eventos, divulgação de colecções, campanhas de restauro, visualização de reservas, dar a conhecer os projectos realizados por 
cada departamento, etc. Adicionalmente, podem também ser utilizados como instrumentos de desenvolvimento de actividades, por exemplo, ao nível dos serviços educativos, como seja a criação de concursos de vídeo ou fotografia cujos trabalhos devem ser publicados on-line.

Quanto ao Flickr destaque-se o projecto The Commons no âmbito do qual várias instituições culturais, nomeadamente bibliotecas e museus, têm vindo a disponibilizar o acesso a colecções de fotografias. Ao nível português conta com a colaboração da Biblioteca de Arte da Fundação Calouste Gulbenkian.

De facto, estas comunidades têm milhões de membros e, como tal, a adesão a estas permite aos museus aproximarem-se de um público abrangente e mundial.

O mesmo se pode dizer das redes sociais on-line, como é o caso do Hi5 em Portugal que de ano para ano tem vindo a acumular membros. Todavia, os resultados obtidos foram quase nulos, o que mostra desconfiança por parte das instituições museológicas portuguesas. Note-se que estas redes, ao permitirem a comunicação e a partilha de recursos variados entre pessoas que partilham interesses comuns, permitem a criação de verdadeiras comunidades de interesse, onde as relações são mais informais, fomentando uma relação mais pessoal com as instituições.

No âmbito do nosso estudo, apenas identificamos um wiki. Contudo, também estes podem ser instrumentos de trabalho úteis no contexto museológico. Por exemplo, um museu pode disponibilizar um wiki às escolas que estejam a desenvolver projectos relacionados com as colecções museológicas, sendo ainda uma excelente ferramenta para tentar recolher junto de um grupo informações sobre determinada temática ou para obter a colaboração da comunidade científica.

Igual resultado foi obtido em relação às Licenças Creative Commons. Todavia, estas apresentam vantagens óbvias: aplicam-se a qualquer conteúdo disponibilizado on-line, agem como complemento ao copyright, são gratuitas e facilmente perceptíveis ao mais comum dos utilizadores que de forma clara toma consciência das condições de utilização dos recursos.

Quanto às restantes ferramentas os resultados foram nulos. Porém também estas podem constituir instrumentos valiosos para a actividade museológica.

Ao nível dos sítios Web, a criação de colecções digitais pessoais, associadas à prática do bookmarking, permite ao utilizador personalizar a sua relação com a dimensão digital do museu, podendo contribuir para o desenvolvimento ou reforço da relação entre o museu e o público, levando o visitante a ver o museu como um espaço que é também seu. $\mathrm{O}$ bookmarking tem a potencialidade de criar um círculo virtuoso (Barry, 2006) entre o museu físico e seu sítio Web, pois à medida que o visitante vai descobrindo novas peças que acrescenta à sua colecção digital, sentirá curiosidade de as visualizar em pessoa. Em contrapartida, sempre que descobrir novos objectos de eleição numa visita física, tenderá a acrescentá-los à sua galeria pessoal. Refira-se, igualmente, que para utilizadores que por razões de distância geográfica nunca poderão deslocar-se às instalações físicas do museu, a relação on-line poderá constituir a única relação que estes irão estabelecer com o museu e suas colecções, muito embora esta vivência não substitua a visita presencial.

Também a prática do social tagging contribui para aproximar o utilizador do museu, intensificando a relação do público com as colecções on-line. Atribuindo palavras-chave às colecções museológicas o utilizador pode ajudar a ultrapassar o fosso semântico entre a linguagem profissional do curador e a linguagem do visitante do museu, ou seja, melhorar a recuperação da informação por parte dos utilizadores dos recursos digitais, aproximando o museu e as suas colecções do visitante e propiciando o estreitar de laços entre uma comunidade que partilha interesses comuns. Entre a comunidade museológica o interesse nesta prática motivou o nascimento do Projecto steve. Este projecto reúne um grupo de profissionais de museus e de 
instituições ligadas a estes numa colaboração para explorar as questões do social tagging.

Quanto aos podcasts, a sua utilização num ambiente museológico pode ser variada: apresentar parte de uma comunicação, difundir mensagens de um artista ou comissário de uma exposição, mas muito particularmente pode ser útil no que se refere a visitas guiadas. De facto, os visitantes podem descarregar podcasts contendo visitas áudioguiadas e podem ouvi-los durante as visitas físicas.

Por sua vez, os RSS feeds, permitindo a actualização dinâmica dos conteúdos de qualquer sítio Web, ajudam a manter os utilizadores ao corrente das novas informações publicadas, sem que seja necessária uma visita efectiva ao sítio Web. No caso dos museus, esta tecnologia pode ajudar a difundir toda e qualquer informação que desejem transmitir, por exemplo, actividades que são organizadas, novas peças que são integradas nas colecções, novos produtos à venda na loja e muito mais. Tudo isto sem que o utilizador tenha que consultar o sítio Web do museu. Esta tecnologia ajuda a tornar realidade a ideia do próprio museu ir ao encontro do visitante e não apenas o inverso.

Logicamente, as ferramentas que aqui apresentamos são apenas exemplos mais populares entre a multiplicidade de ferramentas ao dispor dos museus, cabendo a cada instituição escolher aquela que melhor satisfizer os seus propósitos.

Em muitas situações, o que impede as instituições de adoptarem novas tecnologias são os elevados custos financeiros associados a estas. Todavia, a grande maioria dos serviços Web 2.0 são gratuitos, não exigem conhecimentos tecnológicos profundos, sendo que qualquer utilizador minimamente familiarizado com a Internet consegue operar a este nível. Os museus para desenvolverem projectos desta natureza não necessitam contratar técnicos especializados, um colaborador ou grupo destes pode perfeitamente liderar iniciativas muito interessantes e recompensadoras. O que é necessário é motivar a equipa de trabalho, procurando envolver a instituição como um todo.
De facto, a adopção de ferramentas Web 2.0 é uma tendência que se tem vindo a fazer sentir em várias áreas de actividade, como as bibliotecas (onde o termo "biblioteca 2.0" é já discutido por autores como Jack Maness (2006)) ou até mesmo a política. Veja-se o caso da campanha eleitoral para a presidência norteamericana, na qual pudemos ver o actual presidente Barack Obama a apresentar no sítio Web da campanha links para inúmeras comunidades Web 2.0.

\section{CONCLUSÃO}

Em potencial as ferramentas Web 2.0 podem constituir instrumentos de trabalho muito úteis para a actividade museológica, sobretudo ao nível da relação com os públicos.

Neste contexto, acreditamos que os museus não devem voltar as costas a estes serviços, devam estar atentos aos que já existem e devem procurar informar-se de novos que nasçam, sempre com o objectivo de facilitarem o seu trabalho e de se aproximarem dos públicos, até porque é por pessoas e para pessoas que os museus são pensados e criados.

É importante que a imagem do museu como um lugar apenas voltado para o passado, destinado a intelectuais ou a pessoas mais velhas, seja definitivamente deixada para trás. As ferramentas da Web 2.0 podem ajudar a conferir ao museu uma aura de modernidade no presente, projectando-o no futuro e tornando-o um espaço verdadeiramente aberto ao diálogo multilateral onsite e on-line.

Artigo submetido em 07/06/2009 e aceito em 21/12/2010.

\section{REFERÊNCIAS}

ALVIM, Luísa. Wiki Camilo 2.0. Disponível em: < http://camilo20. wordpress.com/2008/03/04/16/>. Acesso em: 19 dez. 2008.

ANDERSON, Paul. What is Web 2.0?: ideas, technologies and implications for education. JISC Technology \& Standards Watch, feb. 2007. Disponível em: <http://www.jisc.ac.uk/media/documents/ techwatch/tsw0701b.pdf>. Acesso em: 10 ago. 2008.

BARRY, Ailsa. Creating a virtuous circle between a museum's online and physical spaces. In: MUSEUMS AND THE WEB, 2006. Proceedings... Toronto: Archives \& Museum Informatics, 2006. 
Disponível em: <http://www.archimuse.com/mw2006/papers/ barry/barry.html>. Acesso em: 6 Ago. 2008.

BERNERS-LEE, Tim. DeveloperWorks interviews: Tim BernersLee. IBM, 2006. Disponível em: <http:// http://www.ibm.com/ developerworks/podcast/all.html>. Acesso em: 12 Jan. 2009.

BOTTENTUIT JUNIOR, João Batista; COUTINHO, Clara Maria Pereira. As ferramentas da Web 2.0 no apoio à tutoria na formação em e-learning. In: ASSOCIATION FRANCOPHONE INTERNATIONALE DE RECHERCHE SCIENTIFIQUE EN EDUCATION. Tutoria e mediação em educação: novos desafios à investigação científica. Lisboa: AFIRSE, 2008. Disponível em: <http://repositorium.sdum.uminho.pt/bitstream/1822/7767/1/ Afirse\%202008.pdf>. Acesso em: 30 Jul. 2008.

CARDOSO, Gustavo. Internet. Lisboa: Quimera, 2003.

CARVALHO, Ana. Os blogues como instrumentos de trabalho para a museologia. InformaçãoICOM.pt, série 2, n. 1, 2008. Disponível em: $<$ http://www.icom-portugal.org/multimedia/info\%20II-1_junago08\%20UPDATED(2).pdf.>. Acesso em: 10 Ago. 2008.

CREATIVE COMMONS. Disponível em: < http:// creativecommons. pt/cms/view/id/1/>. Acesso em: 10 Dez. 2008.

CRENN, Gaëlle; VIDAL, Geneviève. Les musées français et leurs publics a l'âge du Web 2.0. Nouveaux usages du multimedia et transformations des rapports entre institutions et usagers? In: INTERNATIONAL CULTURAL HERITAGE INFORMATICS MEETING, 2007. Proceedings... Toronto: Archives \& Museum Informatics Europe, 2007. Disponível em: <http://www.archimuse.com/ichim07/ papers/crenn/crenn/html>. Acesso em: 10 Ago. 2008.

FEED. In: Wikipedia. Disponível em: < http://pt.wikipedia.org/ wiki/Feed>. Acesso em: 12 Ago. 2008.

FILIPPINI-FANTONI, Silvia; BOWEN, Jonathan. Bookmarking in museums: extending the museum experience beyond the visit? In: MUSEUMS AND THE WEB, 2007. Proceedings... Toronto: Archives \& Museum Informatics, 2007. Disponível em: <http:// www.archimuse.com/mw2007/papers/filippini-fantoni/filippinifantoni.html>. Acesso em: 6 Ago. 2008.

GOMES, Maria João. Blogs: um recurso e uma estratégia pedagógica. In: SIMPÓSIO INTERNACIONAL DE INFORMÁTICA EDUCATIVA, 7., 2005. Actas... Leiria, 2005. Disponível em: < http:// creazeitao.googlepages.com/BlogsUtilEducUNIVMINHO.pdf>. Acesso em: 10 Ago. 2008.
MANESS, Jack M. Library 2.0 theory: Web 2.0 and its implications for libraries. Webology, vol. 3, n. 2, 2006. Disponível em: <http:// www.Webology.ir/2006/v3n2/a25.html>. Acesso em: 8 Fev. 2009.

MARTY, Paul F. Changing needs and expectations. In: MARTY, Paul F.; JONES, Katherine Burton. Museum informatics: people, information and technology in museums. New York: Routledge, 2007. p. 182-185.

Interactive technologies. In: Museum informatics: people, information and technology in museums. New York: Routledge, 2007. p. 217-221.

MISSÃO para a Sociedade da Informação. Livro verde para a sociedade da informação em Portugal. Lisboa: MSI, 1997. Disponível em: < http:// www.acesso.umic.pt/docs/lverde.htm>. Acesso em: 8 Jan. 2009.

O'REILLY, Tim. What is Web 2.0: design patterns and business models for the next generation of software. O'Reilly Media, 2005. Disponível em: <http://www.oreillynet.com/pub/a/oreilly/tim/ news/2005/09/30/what-is-Web-20.html>. Acesso em: 15 jun. 2008.

Web 2.0 compact definition: trying again. 2006. Disponível em: <http:/ / radar.oreilly.com/2006/12/Web-20-compact-definition-tryi. html>. Acesso em: 15 Jun. 2008.

PODCASTING. In: Wikipedia. Disponível em: < http://pt.wikipedia. org/wiki/Podcasting>. Acesso em: 12 Ago. 2008.

SCHWEIBENZ, Werner. Virtual museums: the development of virtual museums. ICOM News, Paris, v. 57, n. 3, 2004.

THOMAS, Wendy A.; CAREY, Sheila. Actual/virtual visits: what are the links? In: MUSEUMS AND THE WEB, 2005. Proceedings... Toronto: Archives \& Museum Informatics, 2005. Disponível em: <http://www.archimuse.com/mw2005/papers/thomas/thomas. html>. Acesso em: 6 Ago. 2008.

ZORICH, Diane M. Information policy in museums. In: MARTY, Paul F.; JONES, Katherine Burton. Museum informatics: people, information and technology in museums. New York: Routledge, 2007. p. 85-106. 